\title{
EFFECT OF DIFFERENT FINISHING AND POLISHING SYSTEMS ON SURFACE ROUGHNESS AND COLOR CHANGES OF RESIN COMPOSITES: AN IN VITRO STUDY
}

\author{
Ola Barakat* and Muhammad Abbas**
}

\begin{abstract}
Background and objective: Finishing and polishing techniques have great importance on the long-term success and aesthetics of the composite restorations. This study aimed to investigate the effect of three finishing and polishing systems on surface roughness and color changes of four different posterior composites.
\end{abstract}

Materials and Methods: Four different posterior composites, nanohybrid, nano-fill, sonicactivated bulk-fill and microhybrid resin-based composite, and three different finishing and polishing systems, Sof-Lex discs, Astropol ${ }^{\circledR}$ and TOR VM discs were used in the study. The disc specimens (15 disc for each resin composite with total $\mathrm{n}=60$ ) were $10 \mathrm{~mm}$ in diameter and $2 \mathrm{~mm}$ in height. Before and after finishing and polishing procedure, surface roughness was measured with a profilometer device and the Ra values were recorded. Color changes was examined using spectrophotometer and $(\Delta \mathrm{E})$ values were calculated. Data were tabulated and statistically analyzed using analysis of variance and Tukey's test at significance level of $\mathrm{p}<0.05$.

Results: There was no significant difference among the composite resins or the finishing and polishing systems used on surface roughness $(p>0.05)$ although all composites showed a smoother surface after finishing and polishing procedures. As regard to color changes $(\Delta \mathrm{E})$ statistically significant difference was found between composite groups and finishing and polishing system used ( $\mathrm{p}<0.05)$. A direct correlation between $\mathrm{Ra}$ and $\Delta \mathrm{E}$ values was found.

Conclusions: 1.surface roughness and color stability of resin composite restorations depend mainly on the material compositions and polishing procedure. 2 . The effectiveness of the polishing systems was material dependent. 3. Among the material tested, Nanohybrid presented the smoothest surfaces and the least color changed material. 4 . The polishing systems in this study, the best system was the TOR VM discs polishing system with respect to the surface roughness and color changes values. 5. Developments in finishing and polishing systems are important for the creation of ideal restorations and are associated with the increased clinical success of dental practitioners

Key words: finishing and polishing system, posterior composites, surface roughness, profilometer, color changes, spectrophotometer

* Assosciated Professor, Conservative Department, Dentistry program,IbnSina National College for Medical Studies, Jeddah, Saudi Arabia.

** Assistant Professor, Dental Biomaterials, Faculty of Dental Medicine, Al Azhar University Cairo, Egypt 


\section{INTRODUCTION}

The aesthetic appearance and lack of mercury, in addition to other distinctive properties made composite resin a favorite and popular restorative material among clinicians. There are many types of composite materials. They differ as indicated by the filler content that impacting their handling properties and physical qualities. ${ }^{(1)}$

Traditional composites (macrofill) have more than $1 \mu \mathrm{m}$ particle sizes which are difficult to be polished. Therefore, various types of composites with different filler load and size have been developed to provide smooth surface finish and improve composite strength such as microfill (particle size $0.002-0.04 \mu \mathrm{m})$, hybrid $(0.6-1.0 \mu \mathrm{m})$, and nanofilled (20-75 nm). Nanofill resin composite contains only nanoscale particles that have improved surface smoothness, lower shrinkage, color stability, and superior esthetics. ${ }^{(2)}$ Bulk fill composite was introduced to the market to overcome the multistep application of the $2 \mathrm{~mm}$ incremental conventional composites saving clinician's time and provide them with a less technique sensitive material. ${ }^{(3)}$ SonicFill is a sonic-activated bulk fill restorative material. It is different from other bulk fill flowable composites in terms of how it is applied. This material is applied in only one layer up to $5 \mathrm{~mm}$ in thickness. The patented resin highly-filled with special modifiers reacts to sonic energy and the material rapidly flows into the cavity with sonic activation. ${ }^{(4)}$

The proper finishing and polishing of dental restoratives are critical clinical procedures that enhance the esthetics and longevity of restorations. ${ }^{(5)}$ The surface texture of dental materials has a major influence on plaque accumulation, discoloration, wear, and esthetical appearance of direct and indirect restorations. ${ }^{(6)}$ The finishing procedure can remove excess material with particle size of more than $25 \mu \mathrm{m}$, whereas polishing removes particles lesser than $25 \mu \mathrm{m}$. $^{(7)}$

Many different materials and systems have been developed for the finishing and polishing of composite restorations. Tungsten carbide and finegrained diamond burs, stones, rubber burs, and abrasive latex are used in finishing procedures. Aluminum oxide and silicon carbide covered discs, strips, brushes, and polishing pads are then used for the polishing process. ${ }^{(8)}$ Previous studies have shown that smoothest surface of a restoration is attained when the resin is polymerized against an appropriate matrix strip. When such a matrix is not used, polymerization of the outer layer is inhibited, resulting in a surface layer rich in resinous matrix, which has a sticker, softer consistency. ${ }^{(9)}$ Since such a finish cannot be maintained, further contouring and finishing are required. (10) There is lack of enough information regarding the best method used for composite finishing and polishing. Hence, the present in vitro study was performed to evaluate the effect of different finishing and polishing systems on the surface roughness and color of composite resin. The first null hypothesis was that there was no difference between finishing and polishing systems used in this study. The second null hypothesis was that there was no difference among the composite resins in terms of surface roughness and color changes.

\section{MATERIALS AND METHODS}

Four light-cured composites (shade A3): nanohybrid, nano-fill, sonic-activated bulk-fill resinbased composite and microhybrid resin composite, were used in this study. Materials compositions, specifications and manufacturers are listed in Table 1.

Preparation of Resin composite samples; A total of 60 disc samples were prepared with split Teflon mold (10 mm diameter x $2 \mathrm{~mm}$ thickness), fifteen samples for each posterior composite materials. Each mold was slightly over-filled with composite, a clear celluloid band was placed below and over it, and it was then pressed between two glass slides. The glass was later removed and the samples with the band on it were cured using a 
Table (1): Restorative materials used in this study

\begin{tabular}{|c|c|c|}
\hline Resin composite & Composition & Manufacturer \\
\hline $\begin{array}{l}\text { Tetric Evo Ceram: } \\
\text { Nanohybrid resin } \\
\text { composite }\end{array}$ & $\begin{array}{l}\text { Matrix: Dimethacrylates, additives, catalysts, stabilizers, } \\
\text { pigments } \\
\text { Filler(82.5 wt } \% \text { ): Barium glass, ytterbium trifluoride, mixed } \\
\text { oxide, prepolymers, } 68 \% \text { content by volume }\end{array}$ & $\begin{array}{l}\text { Ivoclar Vivadent, Schaan, } \\
\text { Liechtenstein }\end{array}$ \\
\hline $\begin{array}{l}\text { Filter Z350 XT: Nano-fill } \\
\quad \text { resin composite }\end{array}$ & $\begin{array}{l}\text { Matrix: Bis-GMA, UDMA, Bis-EMA 6, and small } \\
\text { quantities of TEGDMA } \\
\text { Filler (78.5wt\%): silica/zirconia cluster fller }(0.6-10 \mu \mathrm{m}) \text {, } \\
\text { zirconia partcles }(4-11 \mathrm{~nm})\end{array}$ & $\begin{array}{l}\text { 3M Dental Products, St Paul, } \\
\text { MN,USA }\end{array}$ \\
\hline $\begin{array}{l}\text { SonicFill Bulk-Fill: Bulk- } \\
\text { fll resin composite }\end{array}$ & $\begin{array}{c}\text { Matrix: Bis-GMA, TEGDMA, Bis-EMA Filler (83.5 wt } \%) \text { : } \\
\text { Barium glass, Silicon dioxide, mixed oxide, additives, } \\
\text { catalysts, stabilizers, and pigments }\end{array}$ & Kerr Corporation, USA \\
\hline $\begin{array}{l}\text { Z250: Microhybrid resin } \\
\text { composite }\end{array}$ & $\begin{array}{c}\text { Matrix: BisGMA, TEGDMA } \\
\text { Filler }(66 \% \text { wt } \%) \text { : Zirconia-silica }(0.04-3.5 \mathrm{um}) \text {, }\end{array}$ & $\begin{array}{l}\text { 3M Dental Products, St Paul, } \\
\text { MN,USA }\end{array}$ \\
\hline
\end{tabular}

TEGDMA: Triethylene glycol dimethacrylate, UDMA: Urethane dimethacrylate, Bis-EMA: Bisphenol-A ethoxylated dimethacrylate, Bis-GMA: Bisphenol-A glycidyl dimethacrylate, Bis-MEPP: Bisphenol 4-methacryloxypolyethoxyphenyl propane

$1,000 \mathrm{~mW} / \mathrm{cm}^{2}$ strength LED (Light Emitting Diode-Elipar, 3M ESPE,Germany) light source. The light output was checked using a radiometer. After curing, the clear bands were removed, the cured samples were finished with six strokes, in the same direction using 600 grit Buehler sandpaper (Lake Bluff, USA) to produce a standard rough surface. Samples were water rinsed and stored for $24 \mathrm{~h}$ at $37^{\circ} \mathrm{C}$ in an incubator $(3 \mathrm{M}$, advanced tech, Cairo, Egy).

\section{Baseline surface roughness measurements} were made for all resin composite disks using USB digital surface profile gauge, (Elcometer 224/2, Elcometer Instruments, Great Britain) and data were recorded using computer software (ElcoMaster 2, Elcometer Instruments). The cut-off value for surface roughness was $0.8 \mathrm{~mm}$, and the traversing distance of the stylus was $5.0 \mathrm{~mm}$. The radius of the tracing diamond tip was $(2.5 \mu \mathrm{m})$, measuring force was $10 \mathrm{mN}$. The machine was repeatedly calibrated after each five samples to assure reliable readings. The surface profile needle was positioned perpendicular over each test specimen performing five readings in different locations of the sample surface. After the five readings, the mean surface roughness values were obtained.

Baseline color measurement were measured using a Reflective spectrophotometer (X-Rite, model RM200QC, Neu-Isenburg, Germany). The aperture size was set to $4 \mathrm{~mm}$ and the specimens were exactly aligned with the device. A white background was selected, and measurements were made according to the CIE L*a*b* color space relative to the CIE standard illuminant D65. The calibration of the spectrophotometer was performed before measurements of each material. Samples of each composite were randomly assigned to one of the three finishing and polishing systems used.

\section{Finishing and Polishing procedure}

The finishing and polishing systems used were: Sof-Lex discs, Astropol ${ }^{\circledR}$ and TOR VM discs. Each system compositions, specifications and manufacturers are listed in (Table 2). 
Table (2): Finishing and polishing systems used in this study

\begin{tabular}{|l|l|l|}
\hline \multicolumn{1}{|c|}{ System } & Composition & Manufacturer \\
\hline Sof-lex discs & $\begin{array}{l}\text { Coarse aluminum oxide disc }(70-90 \mu \mathrm{m}), \text { medium aluminum } \\
\text { oxide disc }(40 \mu \mathrm{m}), \text { fine aluminum oxide disc }(24 \mu \mathrm{m}), \text { and } \\
\text { super-fine aluminum oxide disc }(8 \mu \mathrm{m})\end{array}$ & $\begin{array}{l}\text { 3M-ESPE, Dental } \\
\text { Products, St Paul, MN }\end{array}$ \\
\hline Astropol@ & $\begin{array}{l}\text { F (grey) and P (green): caoutchouc, aluminum oxide, silicon } \\
\text { carbide, titanium oxide, iron oxide } \\
\text { HP (pink): caoutchouc, aluminum oxide, silicon carbide, } \\
\text { titanium oxide, iron oxide, diamond dust }\end{array}$ & $\begin{array}{l}\text { Ivoclar Vivadent, Amherst, NY, } \\
\text { USA }\end{array}$ \\
\hline TOR VM discs & $\begin{array}{l}\text { Coarse }(70-90 \mu \mathrm{m}), \text { medium }(40 \mu \mathrm{m}), \text { fine }(24 \mu \mathrm{m}), \text { and } \\
\text { super-fine aluminum oxide disc }(8 \mu \mathrm{m})\end{array}$ & TOR VM Ltd, Moscow, Russia \\
\hline
\end{tabular}

The same low-speed hand piece at $\leq 25,000$ rpm was used for all systems. The finishing and polishing procedure used consisted of repetitive strokes, ten seconds per step of the system, to prevent heat buildup and formation of grooves. A conscious effort was made to standardize the strokes, downward force, and the number of strokes for each finishing and polishing procedure. According to manufacturer's instructions, Sof-Lex ${ }^{\mathrm{TM}}$ and TOR VM were used dry whereas Astropol ${ }^{\circledR}$ used with water. All samples preparation, finishing, and polishing procedures were done by the same investigator to reduce variability.

After completing the finishing and polishing procedures, the polished resin composite discs were washed, allowed to dry, and kept in $100 \%$ humidity for $24 \mathrm{~h}$, then the surface roughness of the samples was measured again with the same profilometer and the values were recorded. Surface roughness was described by the arithmetic mean of the absolute ordinate values (average roughness $\mathrm{Ra}$, as per ISO 4287). ${ }^{(11)}$

Also, color of the samples was measured again with the same spectrophotometer. The color changes $(\Delta \mathrm{E})$ of the specimens were evaluated using the following formula:

$$
\Delta E=\sqrt{\left\{\left(L_{1}^{*}-L_{2}^{*}\right)^{2}+\left(a_{1}^{*}-a_{2}^{*}\right)^{2}+\left(b_{1}^{*}-b_{2}^{*}\right)^{2}\right\}}
$$

Where: $L^{*}=$ lightness $(0-100), a^{*}=($ change the color of the axis red/green) and $\mathrm{b}^{*}=$ (color variation axis yellow/blue )

Statistical analysis: Data were analyzed using statistical software (SPSS, version 19). Three and two-way analysis of variance, followed by a Tukey multiple comparison test $(\mathrm{p}<0.05)$ was used for statistical analysis. To estimate the correlation between surface roughness and color changes, the Spearman and Pearson correlation tests were used.

\section{RESULTS}

\section{Roughness}

The mean values and standard deviations (SD) for roughness measured by average roughness $(\mathrm{Ra}=\mu \mathrm{m})$ recorded on all resin composite materials before and after different finishing and polishing system summarized in table (3) and graphically represented in figure (1).

Regardless to finishing and polishing system, totally there was no significant difference between different resin composite materials as revealed by three way ANOVA $(\mathrm{P}=0.4505>0.05)$ where (Nanohybrid $\geq$ SonicFill $\geq$ Microhybrid $\geq$ Nano-fill)

Irrespective of resin composite material, totally there was no significant difference between different finishing and polishing systems as indicated by three way ANOVA $(\mathrm{P}=0.5083>0.05)$ where (Soflex $\geq$ Astropol $\geq$ TOR VM) 
All resin composite material showed statistically significant lower roughness mean values after finishing and polishing than before as proven by three way ANOVA $(\mathrm{P}=<0.0001<0.05)$

\section{Color changes}

The mean values and standard deviations $(\mathrm{SD})$ for color changes measured $(\Delta \mathrm{E})$ recorded on all resin composite materials as function of finishing and polishing system summarized in table (4) and graphically represented in figure (2).
Regardless to finishing and polishing system, totally there was significant difference between different resin composite materials as revealed by three-way ANOVA $(\mathrm{P}=<0.0001<0.05)$ where (Microhybrid $>$ Nano-fill $>$ SonicFill $>$ Nanohybrid)

Irrespective of resin composite material, totally there was significant difference between different finishing and polishing systems as indicated by three-way ANOVA $(\mathrm{P}=<0.0001<0.05)$ where (Soflex $>$ Astropol $>$ TOR VM)

TABLE (3): Roughness results (Mean values \pm SD) for all resin composite materials before and after different finishing and polishing system

\begin{tabular}{|c|c|c|c|c|c|c|c|c|}
\hline & & & \multicolumn{6}{|c|}{ Finishing and polishing systems } \\
\hline \multicolumn{3}{|c|}{ Variables } & \multicolumn{2}{|c|}{ Soflex } & \multicolumn{2}{|c|}{ Astropol } & \multicolumn{2}{|c|}{ TOR VM } \\
\hline & & & Mean & $S D$ & Mean & $S D$ & Mean & $S D$ \\
\hline \multirow{8}{*}{$\begin{array}{c}\text { Resin } \\
\text { composite }\end{array}$} & \multirow{2}{*}{ Nanohybrid } & Before & 0.25637 & 0.00038 & 0.2559 & 0.00053 & 0.2559 & 0.00053 \\
\hline & & After & 0.25403 & 0.00062 & 0.25297 & 0.00091 & 0.25483 & 0.00189 \\
\hline & \multirow{2}{*}{ Nano-fill } & Before & 0.25387 & 0.00058 & 0.2539 & 0.00107 & 0.25553 & 0.00184 \\
\hline & & After & 0.2536 & 0.00053 & 0.25443 & 0.00042 & 0.2537 & 0.00073 \\
\hline & \multirow{2}{*}{ SonicFill } & Before & 0.25567 & 0.00011 & 0.25687 & 0.00042 & 0.2542 & 0.00013 \\
\hline & & After & 0.2546 & 0.00047 & 0.25297 & 0.00089 & 0.2537 & 0.00033 \\
\hline & \multirow{2}{*}{ Microhybrid } & Before & 0.25683 & 0.00164 & 0.25487 & 0.00062 & 0.2547 & 0.0014 \\
\hline & & After & 0.254067 & 0.00096 & 0.25397 & 0.00044 & 0.2525 & 0.00073 \\
\hline
\end{tabular}

TABLE (4): Color changes results (Mean values \pm SD) for all resin composite materials before and after different finishing and polishing system

\begin{tabular}{|c|c|c|c|c|c|c|c|}
\hline \multirow{2}{*}{ Variables } & \multicolumn{4}{c|}{ Finishing and polishing systems } \\
\cline { 3 - 8 } & \multicolumn{2}{|c|}{ Soflex } & \multicolumn{2}{c|}{ Astropol } & \multicolumn{2}{c|}{ TOR VM } \\
\cline { 2 - 8 } & \multicolumn{2}{|c|}{ Mean } & SD & Mean & SD & Mean & SD \\
\hline \multirow{3}{*}{$\begin{array}{c}\text { Resin } \\
\text { composite }\end{array}$} & Nanohybrid & 2.571574 & 0.439171 & 1.87748 & 0.15807 & 2.405769 & 0.123742 \\
\cline { 2 - 9 } & Nano-fill & 6.888084 & 0.233137 & 4.70461 & 0.161043 & 2.925426 & 0.149857 \\
\cline { 2 - 8 } & SonicFill & 6.857866 & 0.020015 & 3.029513 & 0.235682 & 2.445345 & 0.178982 \\
\cline { 2 - 8 } & Microhybrid & 9.070432 & 0.266359 & 7.204656 & 0.21899 & 2.768272 & 0.121714 \\
\hline
\end{tabular}




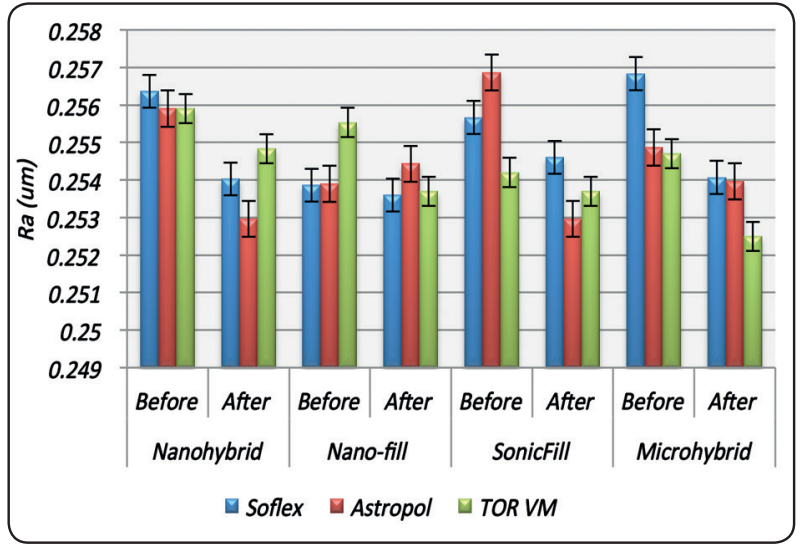

Fig. (1): Column chart showing roughness results mean values for all resin composite materials before and after different finishing and polishing system

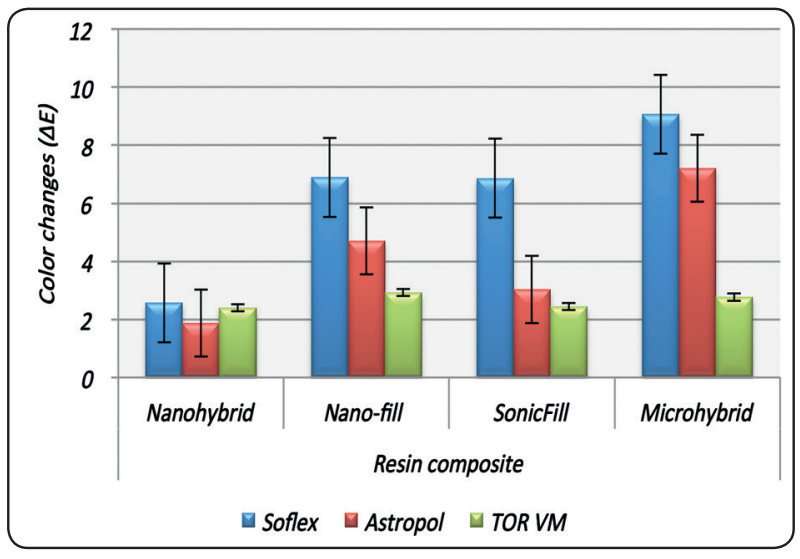

Fig. (2): Column chart showing color changes results mean values for all resin composite materials before and after different finishing and polishing system

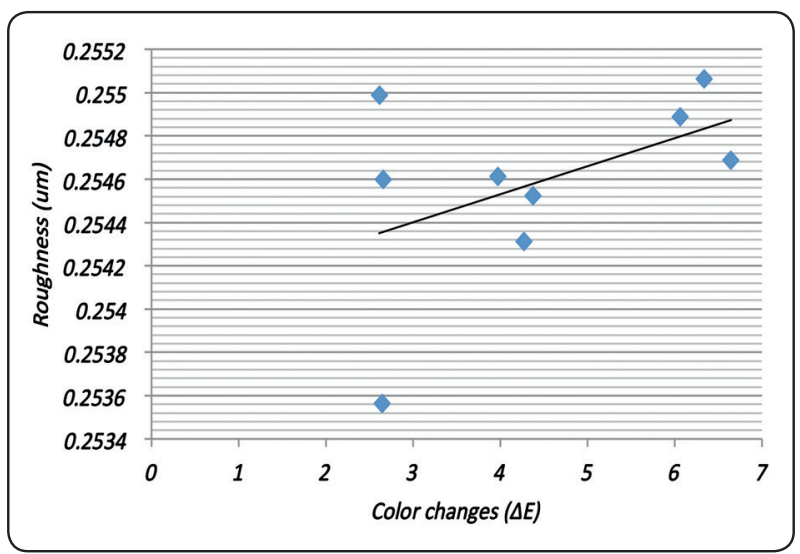

Fig. (3) Linear chart showing correlation between surface roughness and color changes

\section{Correlation between surface roughness and col- or changes;}

The Pearson's correlation coefficient (r) can range from -1 to 1 , inclusive. Positive values indicate a direct correlation, negative values indicate inverse correlation, and when $r$ is 0 , there is no correlation between the factors. Additionally, $r$ values closer to +1 or -1 indicate strong direct or inverse correlation, respectively, whereas $r$ values further away from +1 or -1 indicate weak direct or inverse correlation, respectively.

It was found that there was direct correlation between surface roughness and color changes as indicated by Pearson linear correlation (Correlation coefficient $(r)=-0.4679, r^{2}=0.219$ and $\left.p>0.05\right)$

\section{DISCUSSION}

New developments in adhesive systems and the higher aesthetic prospects of patients have led to a clinically increased use of resin composites. ${ }^{(12)}$ The restorative materials used in this study were selected since they have different filler load and their frequent use in the posterior region. Composite is made up of hard filler component and soft resin matrix. After polishing of restorative material, filler particles are left protruding while resin matrix remains shorter. This results into surface roughness. This can be reduced with use of an effective polishing system. ${ }^{(13)}$

The primary goal of finishing is to obtain a restoration that has good contour, occlusion, healthy embrasure forms, and a smooth surface. Bacterial adhesion to the surface of composite resins and other dental restorative materials is an important factor in causes of secondary caries formation. ${ }^{(9,14)}$ With regard to this feature, plaque formation on the surface of dental restoratives may induce favorable environment for secondary caries, discoloration and/or periodontal disease occurrence. ${ }^{(15,16)}$ An increase in surface roughness may facilitate bacterial adhesion due to the increase in contact area between the material surface and bacterial cells. ${ }^{(17)}$ 
Previous studies reported visibly rough surface with diamond burs. Some researchers claimed that better marginal seal can be obtained if polishing is postponed for $24 \mathrm{~h}$. Others stated that immediate finishing and polishing can result into plastic deformation of the resin. ${ }^{(18-20)}$ Sequential polishing techniques have been regularly used in dental practice to obtain restorations with a smooth surface free of interferences, thus reducing the rates of staining and consequently, color alteration of these materials. ${ }^{(21)}$ Adhesive restorative materials should especially duplicate the natural tooth color. Thus, the performance of a dental restoration depends on its color matching ability and its stability. There are many approaches used to examine the surface roughness of materials such as profilometers, scanning electron microscopy (SEM) analysis and atomic force microscopy (AFM). In the present study, surface profilometer was used to check surface roughness. It has vertical resolution at um level, high speed, reliability, and cannot be damaged easily on use.

In the present study, there was no significant difference among the composite resins or the finishing and polishing system used on surface roughness, the null hypothesis was accepted. Also, it was concluded that after polishing, a smoother surface was achieved. In agreement with the results of this study, several studies have reported that composite resins showed a smoother surface after polishing. ${ }^{(1,8,22-25)}$

The surface texture property of any material results from interactions of several factors. Some of these are internal factors, such as filler (type, shape, dimension, and particle distribution), the resin matrix type, the highest obtainable degree of polymerization, and the effective bonding between the filler and the resinous matrix. ${ }^{(25-27)}$

In the same way as type, size and volume of load particles vary among different composite formulations. These factors interfere in the different procedures of finishing and polishing of the material. The smaller the load particle of a composite, the easier it will be to polish, giving it greater surface smoothness and less presence of micro-failures. ${ }^{(28)}$

It was reported that, Nano-fill contains both nanofillers and nanoclusters which were made of silica and silica/zirconia respectively. Nanocluster filler particles consist of loosely bound agglomerates of nano-sized filler particles. These nano-particles which form the clusters may be worn away, rather than plucking out the whole cluster particles from the resin itself. Moreover, no particle dislodging through SEM images of Nano-fill. Ultimately, the surfaces have smaller defects and better polish retention. On the other hand, the composite materials that contained glass fillers such as Nanohybrid showed rougher surfaces than Nano-fill did when both materials received polishing with the same polishing system. ${ }^{(8)}$

The other external factors affecting the surface texture are related to the finishing and polishing system, such as the elasticity of the material in which the abrasives are embedded, the hardness of the abrasives, and the geometry of the instrument used. ${ }^{(26)}$ Although there are several studies including the polishing systems, it could not be found which evaluated the TOR VM polishing system. As a working principle, the TOR VM is similar to the Sof-Lex finishing discs. The hardness of aluminum oxide is significantly higher than that of silicon dioxide. Aluminum oxide and diamond pastes produce smooth surfaces, whereas diamond points can produce surface scratches. ${ }^{(2)}$

According to previous study, surface roughness $\geq$ $0.2 \mu \mathrm{m}$ promotes greater biofilm retention, leading to an increase in recurrent caries. An increase up to 0.3 $\mathrm{mm}$ may be detected by the patients lips and tongue, causing discomfort. In this study, surface roughness values that contained finishing or polishing systems were $>0.2 \mu \mathrm{m}$, which is the critical size for bacterial adhesion. ${ }^{(29)}$ 
Color changes can be evaluated by visual and/or instrumental techniques. One of these instrumental techniques is spectrophotometry and it is superior to visual evaluation as it leaves no chance for subjective interpretation. It is able to measure the color change $(\Delta \mathrm{E})$ by comparing the values of before and after, according to a formula that has been reported to be a reliable technique. ${ }^{(4)}$

In the present study, there was significant difference among the resins composite and among the finishing and polishing system used on color changes, the null hypothesis was rejected. This finding is in accordance with previous results. ${ }^{(8,24)}$

In the present study, Microhybrid was the highest in color change meanwhile Nanohybrid was the least among tested materials. This might be due to the omission of TEGDMA from its composition. The color alteration observed in this study may be explained by the variation between load particle size present in Microhybrid composite (0.01-3.5 $\mu \mathrm{m})$ and by their volume $(60 \%)$. Larger load particles present a different degree of degradation than that of smaller particles. Considering the direct relation between color perception and the reflection of incident light on the composite, greater the variety in particle size, greater is the scattering of light beams and higher is the color changes of the material. ${ }^{(30)}$

The affinity of the resin matrix to color change can be controlled by its degree of conversion and this degree is exactly affected by the amount of unreacted monomer. Higher monomer conversion leads to low amount of unreacted monomer and better color stability. ${ }^{(31)}$ Also it might be stated that the monomer ingredient of SonicFill could also be related with its higher color changes.

Concerning the color changes in esthetic restorations, three different levels were used to distinguish variations in color values: $\Delta E<1$, imperceptible by the human eye; $1.0<\Delta E<3.3$, appreciated only by a skilled person, clinically acceptable; and $\Delta E$ $>3.3$, easily observed, not clinically acceptable.
(32) In the present study, all of the resin composite groups revealed total values that were $>3.3$ except for nanohybrid type. Also, totally TOR VM discs the only system showed clinically accepted $\Delta E$ It was evidence from the literature that finishing and polishing procedures may influence the composite surface quality and can therefore be related to color change of the resin-based materials. In the present study, the smooth surfaces attained by polishing enhanced the color stability of the resin composite materials tested which was supported by other findings. ${ }^{(33-35)}$

A strained surface of Filtek Supreme XT caused by polishing procedure is more susceptible to staining as reported. ${ }^{(36)}$ Astropol might have strained the composite's surfaces during polishing process. The strain increases the activity of the atoms on the surface and facilitates accumulation of the dye. The strain of the molecular arrangement of the resin matrix may cause detachment of the filler particles from the heat-softened resin.

Within the limitations of this in vitro study the following conclusions could be drawn:

1. Surface roughness and color stability depend mainly on the material composition and secondly on the polishing procedure.

2. The effectiveness of the polishing systems was material dependent.

3. Among the material tested, Nanohybrid presented the smoothest surfaces and the least color changed material

4. The polishing systems in this study, the best system was the TOR VM discs polishing system with respect to the surface roughness and color changes values.

5. Developments in finishing and polishing systems are important for the creation of ideal restorations and are associated with the increased clinical success of dental practitioners. 
Limitation of the present study; The present study is an in vitro test and there could be changes in in vivo results. In our study, sample size was less, and only three polishing systems were examined. There is a need of further research to check other polishing systems with larger samples size

\section{REFERENCES}

1. Koh R, Neiva G, Dennison J, Yaman P. Finishing Systems on the Final Surface Roughness of Composites. J Contemp Dent Pract 2008; 2:138-145.

2. Chour RG, Moda A, Arora A, Arafath MY, Shetty VK, Rishal Y. Comparative evaluation of effect of different polishing systems on surface roughness of composite resin: An in vitro study. J Int Soc Prevent Communit Dent 2016; 6:166-70.

3. Abuelenain DA, Abou Neel EA, Al-Dharrab A. Surface characterization and mechanical behavior of bulk fill versus incremental dental composites. Tanta Dent J 2017; 14:56-61.

4. Toz Akalin T, Genc G, Korkmaz Ceyhan Y, Ozturk Bozkurt F. The effect of mouth rinses on the color stability of sonicfill and a nanohybrid composite. J Istanb Univ Fac Dent. 2016; $50: 17-23$.

5. Magdy NM, Kola MZ, Alqahtani HH, Alqahtani MD, Alghmlas AS. Evaluation of surface roughness of different direct resin-based composites. J Int Soc Prevent Commune Dent 2017; 7:104-9.

6. Morgan M. Finishing and polishing of direct posterior resin restorations. Pract Proced Aesthet Dent 2004; 16:211-7.

7. Gonçalves MA, Teixeira VC, Rodrigues SS, de Oliveira RS, Salvio LA. Evaluation of the roughness of composite resins submitted to different surface treatments. Acta Odontol Latinoam 2012; 25:89-95.

8. Kocaağaoğlu H, Aslan T, Gürbulak A, Albayrak H, Taşdemir Z, Gumus H. Efficacy of polishing kits on the surface roughness and color stability of different composite resins. Niger J Clin Pract 2017; 20:557-65.

9. Kumari CM, Bhat KM, Bansal R. Evaluation of surface roughness of different restorative composites after polishing using atomic force microscopy. J Conserv Dent 2016; 19:56-62.

10. Turssi CP, Ferracane JL, Serra MC. Abrasive wear of resin composites as related to fnishing and polishing procedures. Dent Mater 2005; 21:641-8.

11. Heintze SD, Forjanic M, Rousson V. Surface roughness and gloss of dental materials as a function of force and polishing time in vitro. Dent Mater 2006; 22:146-65.

12. Costa JD, Ferracane J, Paravina RD, Mazur RF, Roeder L. The effect of different polishing systems on surface roughness and gloss of various resin composites. J Esthet Restor Dent 2007; 19:214-224.

13. Abzal MS, Rathakrishnan M, Prakash V, Vivekanandhan P, Subbiya A, Sukumaran VG. Evaluation of surface roughness of three different composite resins with three different polishing systems. J Conserv Dent 2016; 19:1714.

14. Tabatabaee MH, Sakineh A, Asieh R, Maryam G. Monomer release from nanoflled and microhybrid dental composites after bleaching. J Dent Tehran Univ Med Sci 2014; 11:56-66.

15. Bayrak GD, Sandalli N, Selvi-Kuvvetli S, Topcuoglu N, Kulekci G. Effect of two different polishing systems on fluoride release, surface roughness and bacterial adhesion of newly developed restorative materials. J Esthet Restore Dent. 2017; 00:1-11.

16. Erdemir U, Sancakli HS, Yildiz E. The effect of one-step and multistep polishing systems on the surface roughness and microhardness of novel resin composites. Eur J Dent. 2012; 6:198-205.

17. Song F, Koo H, Ren D. Effects of material properties on bacterial adhesion and biofilm formation. J Dent Res. 2015; 94:1027-1034.

18. Madhyastha PS, Naik DG, Srikant N, kotian R, Bhat KM. Effect of fnishing/polishing techniques and time on surface roughness of silorane and methacrylate based restorative materials. Oral Health Dent Manag 2015; 14:212-8.

19. Venturini D, Cenci MS, Demarco FF, Camacho GB, Powers JM. Effect of Polishing Techniques and Time on Surface Roughness, Hardness and Microleakage of Resin Composite Restorations. Oper Dent 2006; 31:11-7.

20. Endo T, Finger WJ, Kanehira M, Utterodt A, Komatsu M. Surface texture and roughness of polished nanofll and nanohybrid resin composites. Dent Mater J 2010; 29:21323.

21. Atabek D, Sillelioglu H, Olmez A. The effciency of a new polishing material: nanotechnology liquid polish. Oper 
Dent 2010; 35:362-369 in de Morais RC, da Fonseca Robert Garcia L, Cruvinel DR, Pires-de-Souza FCP. Color Stability and Surface Roughness of Composite submitted to Different Types and Periods of Finishing/Polishing: Physical Properties of Composites. J Contemp Dent Pract 2015;16:565-570.

22. Buchgraber B, Kqiku L, Allmer N, Jakopic G, Stadtler P. Surface roughness of one nanofill and one silorane composite after polishing. Coll Antropol 2011; 35:879-883.

23. da Costa J, Adams-Belusko A, Riley K, Ferracane JL. The effect of various dentifrices on surface roughness and gloss of resin composites. J Dent 2010;38 Suppl 2: e123-8.

24. Gönülol N, Yilmaz F. The effects of finishing and polishing techniques on surface roughness and color stability of nanocomposites. J Dent 2012;40 Suppl 2: e64-70.

25. Sahbaz C, Bahsi E, Ince B, Bakir E, Cellik O. Effect of the Different Finishing and Polishing Procedures on the Surface Roughness of Three Different Posterior Composite Resins. SCANNING Wiley Periodicals 2016; 9999:1-7.

26. Marghalani HY.Effect of finishing/polishing systems on the surface roughness of novel posterior composites. J Esthet Restor Dent 2010;22:127-138.

27. Yu H, Zhang C-Y, Cheng S-L, Cheng H.. Effects of bleaching agents on dental restorative materials: Areview of theliterature and recommendation to dental practitioners and researchers. J Dent Sci DOI: 2015.http://dx.doi. org/10.1016/j.jds.2014.08.005

28. Choi MS, Lee YK, Lim BS, Rhee SH, Yang HC. Changes in surface characteristics of dental resin composites after polishing.JournalofMaterials Science:MaterialsinMedicine 2005; 16:347-353.
29. Bollenl CML, Lambrechts P, Quirynen M. Comparison of surface roughness of oral hard materials to the threshold surface roughness for bacterial plaque retention: A review of the literature. Dent Mater 1997; 13:258-269.

30. Pires-de-Souza FCP, Garcia Lda F, Hamida HM, Casemiro LA. Color stability of composites subjected to accelerated aging after curing using either a halogen or light emitting diode source. Braz Dent J 2007; 18:119-123.

31. Garoushi S, Lassila L, Hatem M, Shembesh M, Baady L, Salim Z, Vallittu P. Influence of staining solutions and whitening procedures on discoloration of hybrid composite resins. Acta Odontol Scand 2013; 71:144-150.

32. de Alencar eSilva Leite ML, da Cunha Medeiros e Silva FS, Meireles SS, Duarte RM, Andrade AK. The effect of drinks on color stability and surface roughness of nanocomposites. Eur J Dent 2014; 8:330-6.

33. Patel SB, Gordan VV, Barrett AA, Shen C. The effect of surface finishing and storage solutions on the color stability of resin based composites. J Am Dent Assoc. 2004;135:587-94.

34. Lu H, Roeder LB, Lei L, Powers JM. Effect of surface roughness on stain resistance of dental resin composites. J Esthetic and Restorative Dentistry 2005;17:102-108.

35. Sarac D, Sarac YS, Kulunk S, Ural C, Kulunk T. The effect of polishing techniques on the surface roughness and color change of composite resins. J Prosthet Dent. 2006; 96:33-40.

36. Van Noort R and Davis LG. Surface finish of composite resin restorative materials. British Dental Journal 1984; 157: 360-364 